\title{
The development and application of strategic adaptive management within South African National Parks
}

\author{
Authors: \\ Dirk J. Roux ${ }^{1,2}$ \\ Llewellyn C. Foxcroft ${ }^{3,4}$ \\ Affiliations: \\ ${ }^{1}$ South African National \\ Parks, George, South Africa \\ ${ }^{2}$ Sustainability Research \\ Unit, Nelson Mandela \\ Metropolitan University, \\ George, South Africa \\ ${ }^{3}$ South African National \\ Parks, Skukuza, South Africa \\ ${ }^{4}$ Centre for Invasion Biology, \\ Department of Botany \\ and Zoology, Stellenbosch \\ University, South Africa \\ Correspondence to: \\ Dirk Roux \\ Email: \\ dirkr@sanparks.org \\ Postal address: \\ Private Bag X 6531, George \\ 6530, South Africa \\ How to cite this article: \\ Roux, D.J. \& Foxcroft, L.C., \\ 2011, 'The development \\ and application of strategic \\ adaptive management within \\ South African National Parks', \\ Koedoe 53(2), Art. \#1049, \\ 5 pages. doi:10.4102/koedoe. \\ v53i2.1049
}

\section{Introduction}

Adaptive management is an appealing approach to deal with inherent uncertainty in complex and interactive social-ecological systems (Holling 2001; Rogers 2003). In short, adaptive management is about learning-by-doing in a scientific way, adapting behaviour and overall direction as new information becomes available. It provides a structured way for improving our incomplete understanding through an iterative process of setting objectives, implementing policy decisions and evaluating the implications of their outcomes for future decision making. In essence, adaptive management is:

the process of treating natural resource management as an experiment such that the practicality of trial and error is added to the rigour and explicitness of the scientific experiment, producing learning that is both relevant and valid.

(Meffe et al. 2002)

When adaptive management is practiced, policies become hypotheses and management actions become the experiments to test those hypotheses (Folke et al. 2005).

First referred to as adaptive environmental assessment and management (AEAM) (Holling 1978; Walters 1986), adaptive management has grown into an established field of research and practice (Allan \& Stankey 2009; Armitage, Berkes \& Doubleday 2008; Meffe et al. 2002; Oglethorpe 2002; Walters 2002). Whilst there is a rich literature on the philosophical merits of adaptive management, the actual day-to-day implementation had faced many obstacles (Berkes, Colding \& Folke 2003; Johnson 1999; Lee 1993; McLain \& Lee 1996; Rogers 2003; Shea et al. 2002; Walters 1997). Yet a version of adaptive management that developed in South Africa has grown to become an integral part of the thinking, planning and decision-making within South African National Parks (SANParks). This version is referred to as strategic adaptive management (SAM) and this special issue is dedicated to reflecting on the development and implementation of SAM within SANParks and its stakeholder community over a 10-year period.

In this editorial we present a brief introduction to the main components and vocabulary of SAM as practiced by SANParks, as well as a roadmap through the papers that constitute the two parts of the special issue. The papers that follow in this special issue, and the references therein, will provide the reader with a rich source of literature and in-depth treatise of SAM and its development within SANParks.

\section{Strategic adaptive management in SANParks Philosophical foundation}

The century-long evolution of management practices in the Kruger National Park is chronicled in Venter et al. (2008). An optimisation approach in the early years (c.1902-1980), as well as command-and-control (1955-1985) and laissez-faire (1985-1995) approaches were embraced before the adoption of adaptive management in 1995. The appropriateness of adaptive management for natural resource management in general, and its adoption by Kruger National Park, stems from a growing awareness of two critical challenges, (1) the existence of ecological complexity and social complexity and hence social-ecological complexity and (2) the existence of multiple stakeholders with diverse (and often divergent) perceptions, values and expectations.

A defining characteristic of complex systems is that patterns emerge or self-organise from the local interactions between components of the system. The interactions and feedbacks between components can be 'nonlinear', resulting in an inherent degree of unpredictability in cause-andeffect relationships and making them 'knowable' only in retrospect. An emergent property, for example patterns in organism distribution, is not a property of any single agent but of the system as a whole (Levin 1998, 1999; Snowden \& Stanbridge 2004).

The second challenge relates to the multistakeholder nature of common-property natural resources; even fenced-off protected areas are increasingly influenced by external social issues 
(Venter et al. 2008). These stakeholders may subscribe to widely varying world views, based on different values and knowledge forms, with expectations that play out over different time horizons and spatial scales. Under these circumstances, management should probably avoid targeting an optimal solution for 'the (single) problem', but should adopt an ongoing learning and negotiation process where mutual sense-making and adaptation are prioritised (PahlWostl \& Hare 2004). This reality has lead some authors and practitioners to coin the term 'adaptive co-management', as a descriptor of adaptive management that explicitly caters for mutual learning and cooperation between stakeholders such as conservation agencies, researchers and local communities (Armitage et al. 2007; Borrini-Feyerabend et al. 2000; Olsson, Folke \& Berkes 2004; Ruitenbeek \& Cartier 2001).

The presence of limited predictability (or a certain level of irreducible uncertainty), as well as multiple stakeholders with frequent conflicting interests, suggests that there are two fundamental conditions necessary for effective management of natural resources, (1) to learn and adapt and (2) to do so purposefully with relevant partners. SAM, which was initially developed in the context of managing rivers and their catchment areas (Biggs \& Rogers 2003; Rogers \& Bestbier 1997; Rogers \& Biggs 1999), provides a framework for facilitating such learning. It incorporates the iterative learning dimension of adaptive management and the mutual learning dimension of co-management. In addition, it emphasises a forward-looking dimension, hence the reference to 'strategic'. In summary, as Grant et al. (2008) point out, SAM is designed to be strategic (facilitate action with foresight and purpose), adaptive (facilitate learning whilst we are doing) and participatory (facilitate engagement and empowerment of stakeholders).

SAM is a modular process that allows practitioners to start with any of the five broad steps in the adaptive cycle and to expand their efforts from there. The five steps can be grouped into three interrelated subprocesses or components that have taken shape in the application of SAM, namely adaptive planning, adaptive implementation and adaptive evaluation (Figure 1). In the following sections we introduce the basic steps of SAM in more detail.

\section{Adaptive planning}

The adaptive planning process of SAM is seen increasingly as a critical condition for achieving its successful implementation (Rogers pers. comm., 14 September 2010). The aim of this process is to build a sense of common purpose amongst all relevant stakeholders and to develop a collective roadmap for getting from a current (usually undesirable) reality to a more desirable social-ecological system. Stakeholder inclusivity is vital to the success of an adaptive planning process. In the case of SANParks, stakeholders include park managers, scientists, government policymakers, agency managers, wildlife activists, traditional communities neighbouring parks, farmers that share catchments of rivers that flow through parks, NGOs and ecotourists. Successful adaptive planning depends on the facilitation of a constructive

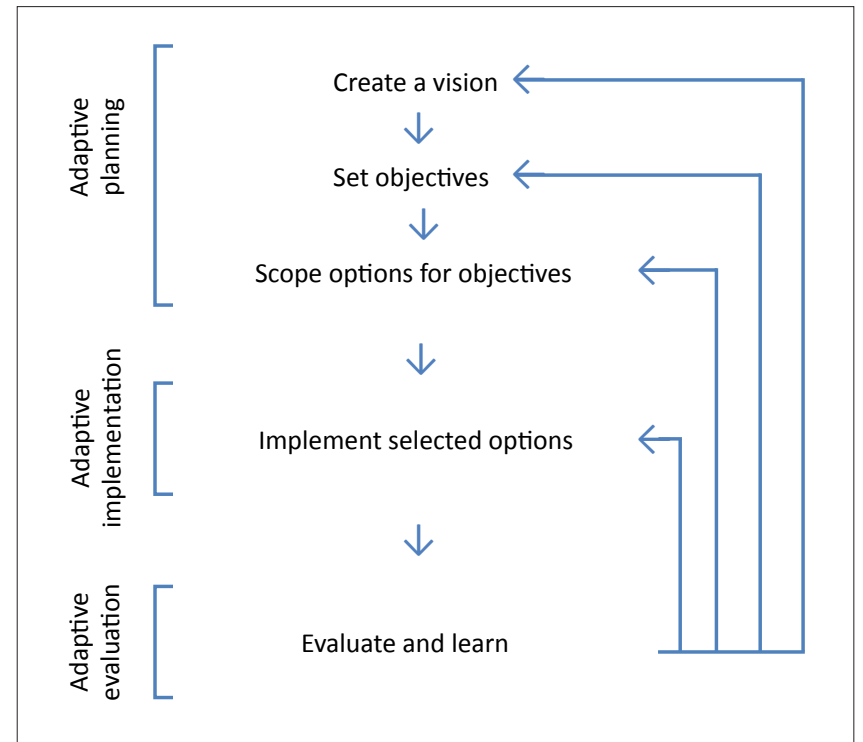

FIGURE 1: Schematic summary of the steps in the strategic adaptive management process, based on the work of Biggs, H.C. \& Rogers, K.H., 2003, 'An adaptive system to link science, monitoring and management in practice', in J.T. du Toit, K.H. Rogers \& H.C. Biggs (eds.), The Kruger experience. Ecology and management of savanna heterogeneity, pp. 59-80, Island Press, Washington DC; Pollard, S.R. \& Du Toit, D.R., 2007, Guidelines for strategic adaptive management - Experiences from managing the rivers of the Kruger National Park. Guidelines of UNEP/GEF Project No. GF/27-13-03-4679. Ecosystems, Protected Areas and People Project; and Scholes, R.J. \& Mennell, K.G., 2008, 'Summary for policymakers', in R.J. Scholes \& K.G. Mennell (eds.), Elephant management: A scientific assessment for South Africa, pp. 1-21, Wits University Press, Johannesburg.

dialogue amongst these stakeholders with their diverse and often divergent values, expectations, professional norms and reward systems (Rogers \& Breen 2003).

The first step in adaptive planning is to create a common vision in which stakeholders agree on the social, technical, economic, ecological and political contexts of the system to be managed. A critical part of this visioning exercise is to reach agreement on values, or operating principles, which should guide management decision making in the future. The V-STEEP (values, social, technical, economic, ecological and political) framework that emerges provides an approach to describing the context as comprehensively as possible (see Pollard \& Du Toit 2007). A further part of visioning is to deliberate and reach consensus on the vital attributes of the system to be managed and their determinants. Vital attributes, as perceived by stakeholders, are the distinctive and special features of the social-ecological system of concern that are the key to its management (Rogers \& Bestbier 1997).

A vision statement is formulated on the basis of this understanding of the context and values. The vision, together with the vital attributes of the system to be managed, informs the setting of objectives. A nested hierarchy of objectives starts with high-level objectives that are set, firstly, to ensure the maintenance of the identified vital attributes of the system to be managed and, secondly, to overcome the constraints and threats to meeting the vision. Through a step-by-step process, these high-level objectives (which are largely based on stakeholder values) are deconstructed into a series of objectives of increasing detail until they represent measurable, scientifically credible endpoints. The result is referred to as an objectives hierarchy (Figure 2). 
Acknowledging the dynamic nature of ecosystems, the measurable targets (Figure 2) describe the boundaries of the desired state (as opposed to an optimal value). These boundaries are also referred to as thresholds of potential concern (TPCs) and are essentially hypotheses of the outer limits of acceptable change. These 'boundaries' are acceptable changes in the attribute of interest, embedded within specific temporal and spatial scales (see Foxcroft \& McGeoch 2011). As such, their validity and appropriateness remains open to challenge and TPCs are revised as understanding of the system improves (Pollard \& Du Toit 2007). TPCs are developed in collaboration between managers, scientists and field staff responsible for monitoring.

The last step that forms part of the adaptive planning process is to scope or analyse various options for achieving the objectives that were derived in the previous step. Importantly, this step is still conducted in cooperation with stakeholders. Different options are identified, their likely consequences predicted and the acceptability of those consequences assessed. Finally, a combination of management options that provide the best potential social-ecological system outcomes and learning opportunities is selected for implementation (Grant et al. 2008; Pollard \& Du Toit 2007).

\section{Adaptive implementation}

Adaptive implementation entails incorporating the options that were selected in the previous step as part of the operating procedures and business routines of the relevant organisation(s). This requires the development of detailed action plans, allocation of the necessary resources and the implementation of those plans. A key component of the adaptive implementation of action plans is to develop monitoring protocols to describe the subject and focus of what to monitor and establish the frequency at which to do so. Monitoring endpoints are linked to the measurable targets (or TPCs) in Figure 2.

Part of the 'new' management procedures is to establish a forum for the regular evaluation of monitoring results against set TPCs, as well as standard procedures for dealing with TPC excedance and for capturing and sharing learning (Pollard \& Du Toit 2007).

\section{Adaptive evaluation}

One of the main purposes of SAM (and adaptive management in general) is to purposefully learn and adapt over time. Therefore, it is essential that learning becomes an explicit step in the strategic adaptive management process (Figure 1). However, learning should not be seen as a mere step to be taken at the end of the process, but should rather occur throughout the planning and implementation phases via a series of feedback loops. Continuous evaluation and learning is facilitated by reflecting on the following questions (Figure 3):

- Is the monitoring adequate, cost effective and feasible?

- Has the intended plan of operation materialised?

- Were the selected options appropriate?

- Were the predicted consequences correct and, if not, why?
- Were the consequences actually acceptable?

- Even if the predicted consequences were correct and are acceptable, are the objectives and vision being met?

\section{Roadmap through this special issue}

The papers contained in this special issue were solicited to capture and share as much as possible of the experience gained by SANParks during the development and implementation of SAM to date. The authors were allowed a fair degree of freedom to ensure that a broad spectrum of perspectives and diverse lessons are captured in the special issue. We refer to the papers in this issue as essays rather than research papers as some of the authors use a narrative writing style to convey their understanding of SAM.

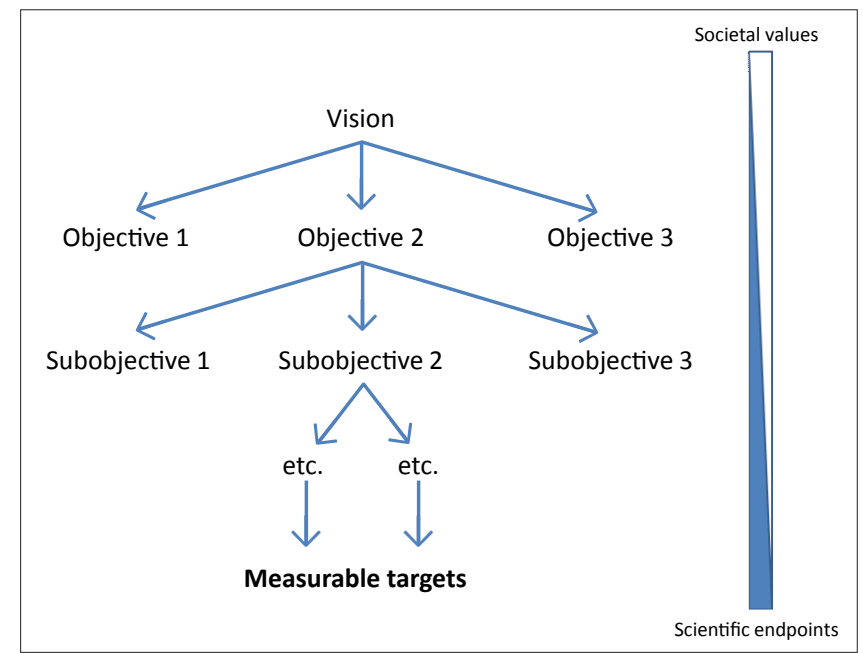

FIGURE 2: Generic objectives hierarchy that links the vision to scientific endpoints, based on the work of Pollard, S.R. \& Du Toit, D.R., 2007, Guidelines for strategic adaptive management - Experiences from managing the rivers of the Kruger National Park. Guidelines of UNEP/GEF Project No. GF/27-13-034679. Ecosystems, Protected Areas and People Project; Rogers, K. \& Bestbier, R., 1997, Development of a protocol for the definition of the desired state of riverine systems in South Africa, Department of Environmental Affairs and Tourism, Pretoria; and Rogers, K.H. \& Biggs, H.C., 1999, 'Integrating indicators, endpoints and value systems in strategic management of the Kruger National Park', Freshwater Biology 41, 439-451. doi:10.1046/j.1365-2427.1999.00441.x.

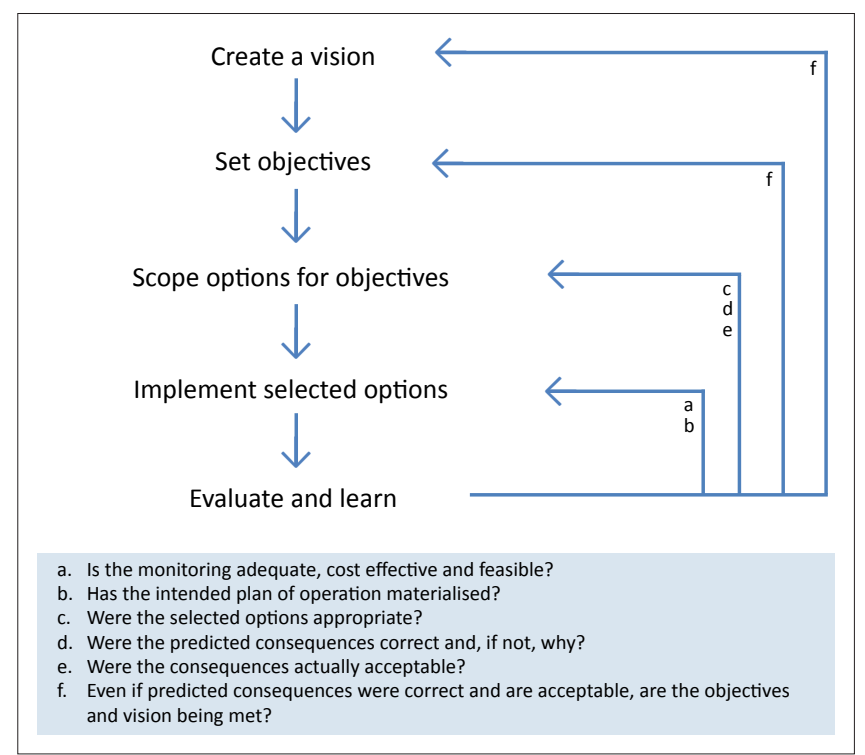

FIGURE 3: The adaptive management process with feedback loops for ongoing reflective learning at multiple points during the process. 
The papers in the special issue can be divided into two parts. Part one consists of papers of a more systemic, generic or philosophical nature, whilst the papers in part two focus largely on thresholds of potential concern and how these thresholds were derived and applied for specific target indicators. Whilst each paper can be read on its own, the papers from part one and part two are meant to be complementary.

Part one starts off with a detailed contextual setting of the Kruger National Park as the main study area for the development of SAM (Pollard et al. 2011). The authors of this essay provide an historical overview of how changes in management paradigms eventually led to the adoption of SAM as the approach of choice, as well as how this approach was pioneered in the sphere of river management. In the next essay, Biggs, Breen, Slotow, Freitag-Ronaldson and Hockings (2011) examine the relationship between assessment and reflection, focusing on how these processes can be used in a complementary way to catalyse learning for adaptive management. Stirzaker et al. (2011) allude to the often contradicting nature of the entrained behaviour of many scientists and managers alike, as well as the behaviour required to participate effectively in an adaptive management process. They explore the shortcomings and requirements of organisations in terms of enabling adaptive management. In the fourth essay, Holness and Biggs (2011) address a question that is of critical importance to a conservation agency: are systematic conservation planning and adaptive management compatible processes? These authors argue that systematic conservation planning should be practiced as an intrinsic part of a broader adaptive management approach and suggest how such a marriage can be achieved. Systematic monitoring is a key factor in our ability to learn and adapt. To this end, McGeoch et al. (2011) propose a framework for biodiversity monitoring which would address the biodiversity objectives as outlined in the management plans of South African National Parks. Gaylard and Ferreira (2011) reflect on how the process of SAM itself has been adapted in response to various implementation challenges. The final essay in part one of this issue provides a transition to the part two papers. Biggs, Ferreira, Freitag-Ronaldson and Grant-Biggs (2011) provide a critical assessment of the usefulness of the concept of thresholds of potential concern. These authors propose a reconceptualisation of the TPC concept, based on learning over a period of one decade, to increase its utility within the SAM process.

Part two contains a collection of 11 essays, each focusing on a specific theme. These essays aim to summarise the development of TPCs for the particular theme and assess how this fits into the broader strategic adaptive management approach. These areas have not received the same amount of attention over the last decade. Therefore, whilst some papers will provide an in-depth discussion of their evolution, others will present recent developments and provide suggestions for future directions. As the pioneering work on SAM in the Kruger National Park was conducted on river management, McLoughlin et al. (2011) take us through a journey explaining the history and rationale behind the TPC concept. Furthermore, they show how the TPCs for river management were used and how they evolved as learning progressed. Fire research and management in SANParks has been an ongoing process for a number of decades, with a number of different approaches being implemented, both within and across parks nationwide. Van Wilgen et al. (2011) discuss the changes from 'trial and error' through to 'active adaptive management', indicating the development of various forms of thresholds. Another area where adaptive management approaches and TPCs have developed over a number of years is with invasive alien species. Here Foxcroft and McGeoch (2011) aim to link the management actions, monitoring programme, research efforts and TPCs in order to develop functional feedback mechanisms and enable improved management and learning.

Whilst not discussing the development of TPCs specifically, a number of essays propose approaches to adopting an adaptive management strategy. They also suggest TPCs and aim to test the use of these in particular cases. For example, Grant et al. (2011) evaluate herbivore-vegetation interactions and how determining thresholds for these can prevent unacceptable changes in desired vegetation states and patterns. McGeoch et al. (2011) deal with approaches to monitoring the often neglected terrestrial and freshwater biodiversity. Similarly, except for some specific case studies, resource use management has been given little attention until recently. In their essay, Scheepers et al. (2011) provide an overall framework for applying adaptive approaches to resource use management. They illustrate this with three case studies, covering a range of approaches and timeframes, and conclude with opportunities for future expansion. As global environmental change intensifies, one of the most pressing issues that conservation and protected area managers face is ensuring the persistence of rare species (Rebelo et al. 2011). However, in areas with high endemicity, and which are facing a number of potentially negative impacts, assessing which species are most in need of special attention is problematic. For example, Table Mountain National Park has 307 threatened IUCN Red List (plus 208 non-least concern) and 332 endemic terrestrial plant and animal species. Rebelo et al. (2011) present an approach to dealing with this challenging problem.Four essays probe some underlying philosophical or technical issues, including the idea that behind all good science lies good science support. This is an essential but underrated part of the overall science management and monitoring partnership. Kruger and MacFadyen (2011) discuss a number of innovations that deal with these issues, from collecting, managing and automating data management, to developing systems to report back on TPCs. A challenge with implementing TPCs is determining at what stage the breach of a TPC is triggered and how the lag effects of this breach are handled. Scholes and Kruger (2011) present a potential approach to this, illustrating it with an example from the Kruger National Park. Owing to the different needs and analytical approaches necessary to implementing TPCs and management across the SANParks estate, Ferreira et al. (2011) use conceptual linkages between objectives, indicators, mechanisms and modulators to help identify key concerns in relation to management objectives. Based on these linkages, the underlying mechanisms responsible for the management concern may be evaluated. 


\section{Conclusion}

The dominant message that emerges from the papers in this special issue is that adaptive management is about structured learning. The authors reflect on various mechanisms that are used to make current assumptions and understanding explicit so that relevant stakeholders can learn in a structured way. These mechanisms include co-creating a desired state or vision, setting objectives, formulating thresholds of potential concern, and monitoring and evaluating the consequences of management decisions. This volume of papers represents a comprehensive documentation and reflection of this process, after applying the principles of SAM across an entire conservation agency for over 10 years.

\section{Acknowledgements}

We thank Dr Richard Stirzaker, Prof. Kevin Rogers and Dr Harry Biggs for discussions and comments during the development of this editorial.

\section{References}

Armitage, D., Berkes, F. \& Doubleday, N., 2007, Adaptive co-management: Collaboration, learning, and multi-level governance, UBC Press, Vancouver.

Berkes, F., Colding, J. \& Folke, C. (eds.), 2003, Navigating social-ecological systems: Building resilience for complexity and change, Cambridge University Press, Cambridge.

Biggs, H., Ferreira, S., Freitag-Ronaldson, S. \& Grant-Biggs, R., 2011, 'Taking stock after a decade: Does the 'thresholds of potential concern' concept need a socio-
ecological revamp?' Koedoe 53(2), Art. \#1002, 9 pages. doi:10.4102/koedoe. ecological

Biggs, H.C., Breen, C., Slotow, R., Freitag, S. \& Hockings, M., 2011, 'How assessment and reflection relate to more effective learning in adaptive management', Koedoe 53(2), Art. \#1001, 13 pages. doi:10.4102/koedoe.v53i2.1001

Biggs, H.C. \& Rogers, K.H., 2003, 'An adaptive system to link science, monitoring and management in practice', in J.T. du Toit, K.H. Rogers \& H.C. Biggs (eds.), The Kruger experience. Ecology and management of savanna heterogeneity, pp. 59-80, Island Press, Washington DC.

Borrini-Feyerabend, G., Farvar, M.T., Nguinguiri, J.C. \& Ndangang, V., 2000, Comanagement of natural resources: Organizing negotiation and learning by doing, Kasparek Zverlag, Heidelberg.

Ferreira, S., Deacon, A., Sithole, H., Bezuidenhout, H., Daemane, M. \& Herbst, M., 2011, 'From numbers to ecosystems and biodiversity: A mechanistic approach to monitoring', Koedoe 53(2), Art. \#998, 12 pages. doi:10.4102/koedoe.v53i2.998

Folke, C., Hahn, T., Olsson, P. \& Norberg, J., 2005, 'Adaptive governance of socialecological systems', Annual Review of Environmental Resources 30, 441-473. doi:10.1146/annurev.energy.30.050504.144511

Foxcroft, L.C. \& McGeoch, M., 2011, 'Implementing invasive species management in an adaptive management framework', Koedoe 53(2), Art. \#1006, 11 pages. in an adaptive management fram
doi:10.4102/koedoe.v53i2.1006

Gaylard, A. \& Ferreira, S., 2011, 'Advances and challenges in the implementation of strategic adaptive management beyond the Kruger National Park - Making linkages between science and biodiversity management', Koedoe 53(2), Art. \#1005, 8 pages. doi:10.4102/koedoe.v53i2.1005

Grant, R., Sherwill, T., Rogers, K., Biggs, H., Freitag, S., Hofmeyr, M., et al., 2008, A framework for developing and implementing management plans for South African National Parks, South African National Parks, Pretoria.

Grant, R.C.C., Peel, M.J.S. \& Bezuidenhout, H., 2011, 'Evaluating herbivore management outcomes and associated vegetation impacts', Koedoe 53(2), Art. management outcomes and associated vegetation

Holling, C.S., 2001, 'Understanding the complexity of economic, ecological and social systems', Ecosystems 4, 390-405. doi:10.1007/s10021-001-0101-5

Holness, S.D. \& Biggs, H.C., 2011, 'Systematic conservation planning and adaptive management', Koedoe 53(2), Art. \#1029, 9 pages. doi:10.4102/koedoe.v53i2.1029

Johnson, B.L., 1999, 'Introduction to the special feature: Adaptive management - Scientifically sound, socially challenged?', Conservation Ecology 3(1), 10, viewed n.d., from http://www.consecol.org/vol3/iss1/art10/

Kruger, J.M. \& MacFadyen, S., 2011, 'Science support within the South African National Parks adaptive management framework', Koedoe 53(2), Art. \#1010, 7 pages. doi:10.4102/koedoe.v53i2.1010

Lee, K., 1993, Compass and gyroscope: Integrating science and politics for the environment, Island Press, Washington DC.

Levin, S.A., 1998, 'Ecosystems and the biosphere as complex adaptive systems', Ecosystems 1, 431-436. doi:10.1007/s100219900037
Levin, S.A., 1999, Fragile dominion: Complexity and the commons, Perseus Publishing, Cambridge.

McGeoch, M.A., Dopolo, M., Novellie, P., Hendriks, H., Freitag, S., Ferreira, S., et al., 2011, 'A strategic framework for biodiversity monitoring in South African National Parks', Koedoe 53(2), Art. \#991, 10 pages. doi:10.4102/koedoe.v53i2.991

McGeoch, M.A., Sithole, H., Samways, M.J., Simaika, J.P., Pryke, J.S., Picker, M., et al., 2011, 'Conservation and monitoring of invertebrates in terrestrial protected areas', Koedoe 53(2), Art. \#1000, 13 pages. doi:10.4102/koedoe.v53i2.1000

McLain, R.J. \& Lee, R.G., 1996, 'Adaptive management: Promises and pitfalls', Environmental Management 20(4), 437-448. doi:10.1007/BF01474647, PMid:8661620

McLoughlin, C.A., Deacon, A., Sithole, H. \& Gyedu- Ababio, T., 2011, 'History, rationale, and lessons learned: Thresholds of potential concern in Kruger National Park river adaptive management', Koedoe 53(2), Art. \#996, 27 pages. doi:10.4102/koedoe. adaptive man

Meffe, G.K., Nielsen, L.A., Knight, R.L. \& Schenborn, D.A., 2002, Ecosystem management: Adaptive community-based conservation, Island Press, Washington DC.

Oglethorpe, J., 2002, Adaptive management: From theory to practice, World Conservation Union, Gland

Ohlsson, L., 1999, Environment, scarcity and conflict: A study of Malthusian concerns, $\mathrm{PhD}$ thesis, University of Gothenburg.

Olsson, P., Folke, C. \& Berkes, F., 2004, 'Adaptive co-management for building resilience in social-ecological systems', Environmental Management 34(1), 75-90. doi:10.1007/s00267-003-0101-7, PMid:15383875

Pahl-Wostl, C. \& Hare, M., 2004, 'Processes of social learning in integrated resources management', Journal of Community and Applied Social Psychology 14, 193-206. doi:10.1002/casp.774

Pollard, S.R. \& Du Toit, D.R., 2007, Guidelines for strategic adaptive management Experiences from managing the rivers of the Kruger National Park. Guidelines of UNEP/GEF Project No. GF/27-13-03-4679. Ecosystems, Protected Areas and People Project, pp. 1-35.

Pollard, S., Du Toit, D. \& Biggs, H., 2011, 'River management under transformation: The emergence of strategic adaptive management of river systems in the Kruger National Park', Koedoe 53 (2), Art. \#1011, 14 pages. doi:10.4102/koedoe. v53i2.1011

Rebelo, T.G., Freitag, S., Cheney, C. \& McGeoch, M.A., 2011, 'Prioritising species of special concern for monitoring in Table Mountain National Park: the challenge of a species-rich, threatened ecosystem', Koedoe 53(2), Art. \#1019, 14 pages. doi:10.4102/koedoe.v53i2.1019

Rogers, K., 2003, 'Adopting a heterogeneity paradigm: Implications for management of protected savannas', in J.T. du Toit, K.H. Rogers \& H.C. Biggs (eds.), The Kruger experience. Ecology and management of savanna heterogeneity, pp. 41-58, Island Press, Washington DC.

Rogers, K.H., Roux, D.J. \& Biggs, H.C., 2000, 'Challenges for catchment management agencies. Lessons from bureaucracies, business and resource management', Water SA 26, 505-512.

Rogers, K. \& Bestbier, R., 1997, Development of a protocol for the definition of the desired state of riverine systems in South Africa, Department of Environmental Affairs and Tourism, Pretoria.

Rogers, K.H. \& Biggs, H.C., 1999, 'Integrating indicators, endpoints and value systems in strategic management of the Kruger National Park', Freshwater Biology 41, 439-451. doi:10.1046/j.1365-2427.1999.00441.x

Ruitenbeek, J. \& Cartier, C., 2001, The invisible wand: Adaptive co-management as an emergent strategy in complex bio-economic systems. Occasional paper no. 34. Center for International Forestry Research, Bogor.

Scheepers, K., Swemmer, L. \& Vermeulen, W.J., 2011, 'Applying adaptive management in resource use in South African National Parks: A case study approach', Koedoe 53(2), Art. \#999, 14 pages. doi:10.4102/koedoe.v53i2.999

Scholes, R.J. \& Kruger, J.M., 2011, 'A framework for deriving and triggering thresholds for management intervention in uncertain, varying and time-lagged systems', Koedoe 53(2), Art. \#987, 8 pages. doi:10.4102/koedoe.v53i2.987

Scholes, R.J. \& Mennell, K.G., 2008, 'Summary for policymakers', in R.J. Scholes \& K.G. Mennell (eds.), Elephant management: A scientific assessment for South Africa, pp. 1-21, Wits University Press, Johannesburg.

Shea, K., Possingham, H.P., Murdoch, W.W. \& Roush, R., 2002, 'Active adaptive management in insect pest and weed control: Intervention with a plan for learning', Ecological Applications 12(3), 927-936. doi:10.1890/10510761(2002)012[0927:AAMIIP]2.0.CO;2

Snowden, D. \& Stanbridge, P., 2004, 'The landscape of management: Creating the context for understanding social complexity', Emergence: Complexity and Organization 6(1-2), 140-148.

Stirzaker, R.J., Roux, D.J. \& Biggs, H.C., 2011, 'Learning to bridge the gap between adaptive management and organisational culture', Koedoe 53(2), Art. \#1007, 6 pages. doi:10.4102/koedoe.v53i2.1007

Swemmer, L.K. \& Taljaard, S., 2011, 'SANParks, people and adaptive management: Understanding a diverse field of practice during changing times', Koedoe 53(2), Art. \#1017, 7 pages. doi:10.4102/koedoe.v53i2.1017

Van Wilgen, B.W., Govender, N., Forsyth, G.G. \& Kraaij, T., 2011, 'Towards adaptive fire management for biodiversity conservation: Experience in South African National Parks', Koedoe 53(2), Art. \#982, 9 pages. doi:10.4102/koedoe.v53i2.982

Venter, F.J., Naiman, R.J., Biggs, H.C. \& Pienaar, D.J., 2008, 'The evolution of conservation management philosophy: Science, environmental change and social adjustments in Kruger National Park', Ecosystems 11, 173-192. doi:10.1007/ s10021-007-9116-x

Walters, C., 1997, 'Challenges in adaptive management of riparian and coastal ecosystems', Conservation Ecology 1(2), 1, viewed n.d., from http://www. consecol.org/vol1/iss2/art1/ 